\title{
Body Mass Index, Haemoglobin, and Total Lymphocyte Count as a Surrogate for CD4 Count in Resource Limited Settings
}

\author{
Louis Boafo Kwantwi, ${ }^{1}$ Bismark Kwame Tunu, ${ }^{1}$ Daniel Boateng, ${ }^{2}$ and Dan Yedu Quansah ${ }^{3}$ \\ ${ }^{1}$ Department of Molecular Medicine, Kwame Nkrumah University of Science and Technology, Kumasi, Ghana \\ ${ }^{2}$ School of Public Health, Kwame Nkrumah University of Science and Technology, Kumasi, Ghana \\ ${ }^{3}$ Department of Biomedical and Forensic Sciences, University of Cape Coast, Cape Coast, Ghana \\ Correspondence should be addressed to Louis Boafo Kwantwi; kwantwiboafo@yahoo.com
}

Received 24 December 2016; Revised 8 March 2017; Accepted 29 March 2017; Published 18 April 2017

Academic Editor: Swasti Tiwari

Copyright (C) 2017 Louis Boafo Kwantwi et al. This is an open access article distributed under the Creative Commons Attribution License, which permits unrestricted use, distribution, and reproduction in any medium, provided the original work is properly cited.

\begin{abstract}
Background. In view of the lack of evidence on the possibility of an economically viable, easy, and readily available biomarker to substitute the traditional role of CD4 counts in HIV disease progression, this study seeks to investigate the potential use of body mass index (BMI), haemoglobin ( $\mathrm{Hb}$ ), and total lymphocyte count (TLC) as surrogate biomarkers for monitoring the disease. Methods. This cross-sectional study was undertaken at the antiretroviral clinic (ART) of the Bomso Hospital, Kumasi, Ghana. We recruited 384 individuals who were 18 years or older and confirmed HIV seropositive patients. Blood samples were assayed for TLC and $\mathrm{Hb}$. Weight and height were determined and BMI was calculated. Result. At a cut-off point of $12.15 \mathrm{~g} / \mathrm{dL}, \mathrm{Hb}$ had sensitivity and specificity of $73.9 \%$ and $56.8 \%$, respectively, whereas BMI had $69.6 \%$ and $80.1 \%$ sensitivity and specificity, respectively. The sensitivity and specificity were also $100 \%$ among the studied participants at a cut-off point of $1200 \mathrm{~mm}^{-3}$ for TLC. There was a significant positive correlation between CD4 count and $\mathrm{Hb}$ (rho 0.262, $p=0.0001$ ), BMI (rho 0.301, $p=0.0001$ ), and TLC (rho $0.834, p=0.0001$ ). Conclusion. The study demonstrates that TLC, Hb, and BMI may provide some useful prognostic information independent of that provided by CD4 count.
\end{abstract}

\section{Introduction}

HIV/AIDS infection continues to pose threats to patients due its devastating effect on the human CD4 cells [1]. The HIV/AIDS virus's ability to weaken the immune system results in a number of disorders including wasting syndrome [2], hematological derangements such as anemia [3], lymphopenia [4], and thrombocytopenia [5] which are the most common cause of HIV related mortality and morbidity [6].

In recent times one of the greatest challenges in the management and care of HIV in poor resource settings has been the evaluation of CD4 count measurement; a parameter which is seen as a traditional biomarker for predicting the progression and monitoring treatment response to highly active antiretroviral therapy (HAART) [7]. The frequency with which costly CD4 counts are administered to monitor treatment efficacy as well as therapeutic regimens continues to be a burden to many underdeveloped countries; therefore the need for an alternate cost effective, easily performed, and readily available surrogate markers that can assist in predicting the disease progression and patient's response to HAART is needed in these settings.

Among HIV infected individuals, studies have indicated a positive association between higher BMI [8], TLC (1200 cell/ ul) [9], and $\mathrm{Hb}$ [10] (less than $10 \mathrm{~g} / \mathrm{dL}$ ) with $\mathrm{CD} 4$ counts $\left(<350\right.$ and $<200$ cells $\left./ \mathrm{mm}^{3}\right)$. A study reports that, being obese or overweight was independently associated with higher CD4 counts, compared to their nonobese $\left(18.5-24.9 \mathrm{~kg} / \mathrm{m}^{2}\right)$ controls [11]. Decrease in Hb levels correlates positively with CD4 cell counts [12]. Anemia, an independent predictor of HIV/AIDS progression, has been found to improve with antiretroviral treatment [10]. Several studies have also indicated adequate sensitivity and specificity to consider TLC as a surrogate measure for CD4 count [13]. Despite these successes, few studies have evaluated the predictability of 
$\mathrm{BMI}, \mathrm{Hb}$, and TLC as surrogate markers to CD4 counts in Ghana.

In view of the lack of evidence on the possibility of an economically viable, easy, and readily available biomarker to substitute the traditional role of CD4 counts in HIV disease progression, this study investigated the potential use of BMI, $\mathrm{Hb}$, and TLC as surrogate biomarkers for monitoring HIV disease progression in Ghana.

\section{Methods}

2.1. Participants and Study Design. This cross-sectional study was undertaken at the ART clinic of the Bomso hospital in the Ashanti region of Ghana from August 2015 to March 2016. We recruited a total of 384 individuals who were 18 years or older and were confirmed HIV seropositive patients at the facility. Our subjects included 208 HIV HAART and 176 HIV HAART naïve patients. Participants who were pregnant and had HIV confections including other opportunistic infections were excluded from the study.

We categorized participants into three groups based on their CD4 lymphocyte counts in accordance with the Center for Disease Control classification. The groups were CD4 counts less than $200 \mathrm{~mm}^{-3}$, between 200 and $499 \mathrm{~mm}^{-3}$, whereas the third group consisted of patients with CD4 count above $500 \mathrm{~mm}^{-3}$. All study protocol was reviewed and approved by the Committee on Human Research and Publication of the Kwame Nkrumah University of Science and Technology (KNUST) and informed consent was also sought from all the participants.

2.2. Measurement of BMI. We measured the weight of participants at baseline during their periodic ART clinic visits. The height of subjects was however measured during their first visit only. Height was measured with a stadiometer and rounded to the nearest $0.1 \mathrm{~cm}$. The Tanita HD-351 Scale was used for weight measurement and rounded to the nearest $0.05 \mathrm{~kg}$. BMI was calculated using the formula (body weight in kilograms)/(height in meters $)^{2}$.

2.3. Measurement of CD4 Counts, Haemoglobin, and T Lymphocyte. CD4 counts, $\mathrm{Hb}$, and TLC were measured by drawing $3 \mathrm{~mL}$ of venous blood from each participant under sterile conditions after applying a tourniquet for less than a minute into anticoagulated sequestrene bottles (EDTA). A complete blood count, including $\mathrm{Hb}$, white blood counts, and lymphocytes with automated differential, was measured. The TLC was calculated by multiplying the white blood count by the automated percent lymphocytes. The full blood count was determined using an autoanalyzer (Cell DNY 1800 from Abbott Diagnostics Division, USA). CD4 analysis was done with the use of the Becton Dickenson and company haematological analyzer called the BD FACSCount from California in USA. The BD FACSCount system used flow cytometry for the quantification of the CD4 T lymphocytes. The laboratory analysis followed a standard flow cytometry performed in laboratories certified by the National Institute of Allergies and Infectious Diseases (NIAID) Flow Cytometry Quality Assessment Program.

2.4. Data Analysis. All statistical analyses were performed with SPSS version 22. Data were presented as median interquartile range (IQR) for nonparametric variables whiles grouped variables were expressed as proportions. We performed a Mann-Whitney $U$ test to compare the differences between HAART naïve and HAART patients for $\mathrm{Hb}, \mathrm{BMI}$, and TLC. Kruskal-Wallis test was performed to determine the extent to which $\mathrm{Hb}, \mathrm{BMI}$, and TLC influence HIV disease progression. We further performed a linear regression test to determine the associations that exist between CD4 count and $\mathrm{Hb}, \mathrm{BMI}$, and TLC. Suitable cut-off point was determined for $\mathrm{Hb}, \mathrm{BMI}$, and TLC using Youden's index. The performance of $\mathrm{Hb}, \mathrm{BMI}$, and TLC was assessed using the area under the curve from the receiver operator characteristics. Positive and negative predictive values were also calculated. All statistical significance were accepted at $p<0.05$.

\section{Results}

3.1. Baseline Characteristics of Study Participants. Table 1 shows the demographic and clinical characteristics of the study participants. Out of the three hundred and eightyfour (384) participants, the majority $(69.8 \%)$ were females in both the HAART and the HAART untreated patients. The median age of the HAART group ( $41 \mathrm{yrs}$ ) was not statistically different from the HAART untreated group ( $40 \mathrm{yrs}$ ). The median CD4 counts of the HAART group $\left(458 \mathrm{~mm}^{-3}\right)$ were significantly higher than the HAART untreated group $\left(229 \mathrm{~mm}^{-3}\right) ; p<0.0001$. The median BMI, Hb, and TLC of HAART patients were significantly different from the HAART untreated patients as detailed in Table 1.

\subsection{Hb, BMI, and Total Lymphocyte Count in HIV Disease} Progression. Table 2 describes the trend of $\mathrm{Hb}, \mathrm{BMI}$, and $\mathrm{T}$ lymphocyte in the disease progression. $\mathrm{Hb}, \mathrm{BMI}$, and TLC were found to decrease significantly $(p \leq 0.0001)$ as the disease progresses with lowest median values among patients with CD4 less than $200 \mathrm{~mm}^{-3}$ for $\mathrm{Hb}(11.4 \mathrm{~g} / \mathrm{dL}), \mathrm{BMI}$ $\left(19.2 \mathrm{~kg} / \mathrm{m}^{2}\right)$, and TLC $\left(1989 \mathrm{~mm}^{-3}\right)$.

3.3. Predictive Performance of Haemoglobin, BMI, and Total Lymphocyte Count. Table 3 describes the predictive performance of $\mathrm{Hb}, \mathrm{BMI}$, and TLC in predicting HIV disease progression among the studied participants: HAART and the HAART untreated. At a cut-off point of $12.15 \mathrm{~g} / \mathrm{L}, \mathrm{Hb}$ had sensitivity and specificity of $73.9 \%$ and $56.8 \%$, respectively, while BMI had $69.6 \%$ and $80.1 \%$ for sensitivity and specificity, respectively. The sensitivity and specificity were also $100 \%$ among the studied participants at a cut-off point of $1200 \mathrm{~mm}^{-3}$ for TLC. The area under the curve for $\mathrm{Hb}$, BMI, and TLC was $0.688,0.780$, and 1.000 , respectively, for the total study participants. The area under the curve of all the biomarkers was very high in both HAART and HAART untreated patients. In the HAART patients, the area under 
TABLE 1: Demographic and clinical characteristics of the studied participants.

\begin{tabular}{lccr}
\hline Parameter & Total subjects (384) & HAART group (208) & HAART naïve (176) \\
\hline Age $($ yrs. $)$ & $40(34-50)$ & $41(35-53)$ & $40(31.3-50)$ \\
Sex $(n, \%)$ & $116(30.2)$ & $62(16.1)$ & $54(14.1)$ \\
$\quad$ Male & $268(69.8)$ & $146(38.0)$ & $122(31.8)$ \\
$\quad$ Female & $346.5(202-503.3)$ & $458.0(307.5-633.8)$ & $229.0(136.3-338.8)$ \\
CD $4\left(\mathrm{~mm}^{-3}\right)$ & $12.1(10.2-15.1)$ & $13.4(12.6-14.2)$ & $10.6(10.4-12.8)$ \\
Hb $(\mathrm{g} / \mathrm{dL})$ & $22.9(19.7-29.9)$ & $26.3(24.3-28.9)$ & $23.5(19.1-24.9)$ \\
BMI $\left(\mathrm{kg} / \mathrm{m}^{2}\right)$ & $2615(1232-3336)$ & $3225(2547-3230)$ & $1989(1145-2605)$ \\
T lymphocyte $\left(\mathrm{mm}^{-3}\right)$ & & & \\
\hline
\end{tabular}

HAART highly active antiretroviral therapy.

TABLE 2: Haemoglobin, BMI, and total lymphocyte count in HIV disease progression.

\begin{tabular}{|c|c|c|c|c|}
\hline \multirow{2}{*}{ Parameter } & \multicolumn{3}{|c|}{ CD4 count } & \multirow{2}{*}{$p$ value } \\
\hline & $<200$ & $200-499$ & $\geq 500$ & \\
\hline \multicolumn{5}{|c|}{ Total } \\
\hline BMI $\left(\mathrm{kg} / \mathrm{m}^{2}\right)$ & $19.2(17.9-21.9)$ & $23.9(21.1-27.3)$ & $24(22.1-28.6)$ & $<0.0001$ \\
\hline $\mathrm{Hb}(\mathrm{g} / \mathrm{dL})$ & $11.4(10.1-12.225)$ & $12.2(11.2-13.1)$ & $12.6(11.7-13.6)$ & $<0.0001$ \\
\hline T lymphocyte $\left(\mathrm{mm}^{-3}\right)$ & $1114(1087-1161)$ & $2595(2307-2837)$ & $3534(3476-3650)$ & $<0.0001$ \\
\hline \multicolumn{5}{|c|}{ HAART group } \\
\hline BMI $\left(\mathrm{kg} / \mathrm{m}^{2}\right)$ & $11.8(11.35-12.15)$ & $12.4(11.55-13.25)$ & $13.5(11.65-15.55)$ & 0.153 \\
\hline $\mathrm{Hb}(\mathrm{g} / \mathrm{dL})$ & $21.7(19.5-24.8)$ & $25.6(20.4-26.1)$ & $27.1(23.4-29.9)$ & 0.005 \\
\hline T lymphocyte $\left(\mathrm{mm}^{-3}\right)$ & $1122(1072-1172)$ & $2680(2490-2990)$ & $3550(3477-3650)$ & $<0.0001$ \\
\hline \multicolumn{5}{|c|}{ HAART naïve group } \\
\hline BMI $\left(\mathrm{kg} / \mathrm{m}^{2}\right)$ & $10.0(9.73-11.50)$ & $11.70(10.90-12.90)$ & $12.0(10.75-13.15)$ & 0.027 \\
\hline $\mathrm{Hb}(\mathrm{g} / \mathrm{dL})$ & $18.2(19.2-22.9)$ & $22.5(20.1-24.6)$ & $23.9(22.6-27.4)$ & $<0.0001$ \\
\hline T lymphocyte $\left(\mathrm{mm}^{-3}\right)$ & $1122(1072-1172)$ & $2680(2490-2990)$ & 3477 (3394-3509) & $<0.0001$ \\
\hline
\end{tabular}

TABLE 3: Predictive performance of hemoglobin, BMI, and total lymphocyte count in predicting CD4 counts $<200 \mathrm{~mm}^{-3}$.

\begin{tabular}{|c|c|c|c|c|c|c|}
\hline Parameter & Cut-off & Sensitivity & Specificity & PPV & NPV & AUC \\
\hline \multicolumn{7}{|c|}{ Total } \\
\hline $\mathrm{Hb}$ & 12.15 & $73.9 \%$ & $56.8 \%$ & $67.4 \%$ & $21.2 \%$ & 0.688 \\
\hline BMI & 20.65 & $69.6 \%$ & $80.1 \%$ & $71.7 \%$ & $51.4 \%$ & 0.780 \\
\hline Total lymphocyte count & 1200 & $100 \%$ & $100 \%$ & $91.3 \%$ & $87.6 \%$ & 1.000 \\
\hline \multicolumn{7}{|c|}{ HAART } \\
\hline $\mathrm{Hb}$ & 12.15 & $70 \%$ & $63.8 \%$ & $52.6 \%$ & 28.7 & 0.679 \\
\hline BMI & 20.35 & $60 \%$ & $77.8 \%$ & $50 \%$ & $56.4 \%$ & 0.787 \\
\hline Total lymphocyte count & 1219 & $90 \%$ & $100 \%$ & $100 \%$ & $81.9 \%$ & 1.000 \\
\hline \multicolumn{7}{|c|}{ HAART naïve } \\
\hline $\mathrm{Hb}$ & 10.35 & $41.7 \%$ & $90.4 \%$ & $36.1 \%$ & 73.1 & 0.658 \\
\hline BMI & 22 & $77.7 \%$ & $78.8 \%$ & $72.2 \%$ & $80.8 \%$ & 0.817 \\
\hline Total lymphocyte count & 1200 & $100 \%$ & $100 \%$ & $91.7 \%$ & $100 \%$ & 1.000 \\
\hline
\end{tabular}

the curve was $0.679,0.789$, and 1.00 for $\mathrm{Hb}, \mathrm{BMI}$, and TLC, respectively, whereas, in the HAART untreated patients, this was $0.658,0.817$, and 1.00 for $\mathrm{Hb}, \mathrm{BMI}$, and TLC, respectively.

TLC had the highest positive $(91.3 \%)$ and negative predictive (87.6\%) values followed by BMI (PPV 71.7\%, NPV 51.4\%). $\mathrm{Hb}$ had the lowest positive (67.4\%) and negative predictive (21.2\%) values.

Figures 1,2, and 3 are scatter plots depicting the correlations of CD4 count with $\mathrm{Hb}, \mathrm{BMI}$, and TLC. There was a significant positive correlation between CD4 count and haemoglobin (rho 0.262, $p=0.0001$ ), BMI (rho 0.301, $p=$ 0.0001 ), and TLC (rho 0.834, $p=0.0001$ ).

\section{Discussion}

This study was conducted to assess whether $\mathrm{Hb}, \mathrm{BMI}$, and TLC can be used as a surrogate for CD 4 count. The use of CD 4 counts to assess disease progression and to guide treatment 


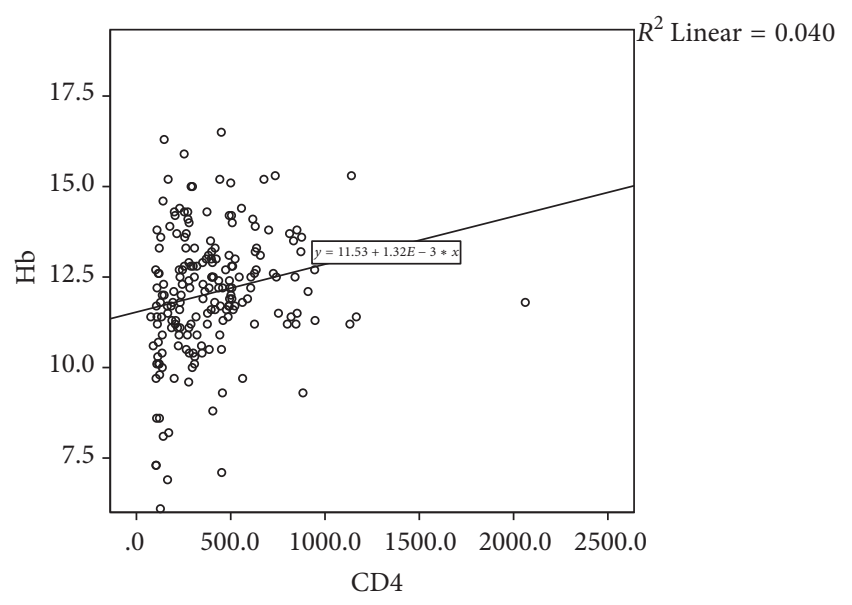

FIGURE 1: Scatter plots depicting the correlations of CD4 count and haemoglobin $(\mathrm{Hb})$.

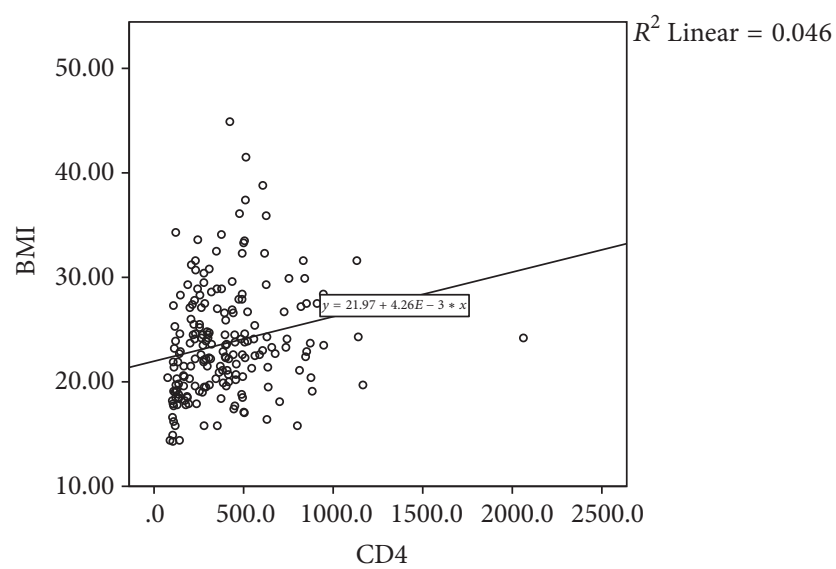

Figure 2: Scatter plots depicting the correlations of CD4 count and body mass index (BMI).

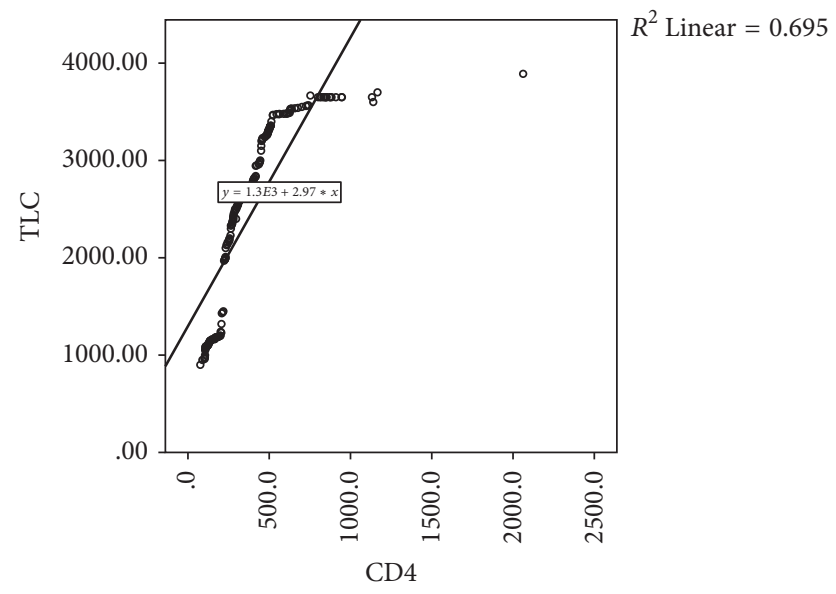

FIGURE 3: Scatter plots depicting the correlations of CD4 count and total lymphocyte count (TLC).

among HIV positive persons is well established. The cost implication of CD4 testing however has sprouted the need to find a less expensive surrogate maker in limited resource settings. Previous evidence has shown the possibility of using TLC in this regard, although there has been lack of consensus on the cut-off for sensitivity or specificity. There has also been the call to assess other surrogate biomarkers that could be used in place of CD4 counts. This study sought to access the suitability of $\mathrm{Hb}, \mathrm{BMI}$, and TLC as surrogates for CD4 counts, using Youden's $J$ index to establish the cuff-off where sensitivity and specificity are the highest.

This study was found TLC to be a good predictor of CD 4 counts. At the cut-off of 1200 cells $/ \mathrm{mm}^{3}$, a sensitivity and specificity of $100 \%$ were observed for patients who were not on HAART treatment. The overall diagnostic performance using the AUC was equally very high $(\mathrm{AUC}=1)$ in both HAART treated and HAART untreated groups thus indicating the use of TLC as a potential surrogate marker in remote and deprived areas of Ghana where scarcity of laboratory technologies is a good choice. Total lymphocyte count at a cut-off of 1200 cells $/ \mathrm{mm}^{3}$ is a good substitute for CD4 $<200 \mathrm{cell} / \mathrm{mm}^{3}$ in remote and deprived areas of Ghana: thus, all individuals who need medication would be given the needed medication if a total lymphocyte count of 1200 cells $/ \mathrm{mm}^{3}$ was used, as recommended by the WHO. Also, patients in the advanced stage of the disease could be identified and given the needed attention and treatment if a cut-off of 1200 cells $/ \mathrm{mm}^{3}$ is used as a surrogate for CD 4 count in our settings. This corroborates previous evidence that also found a high sensitivity and specificity for the same cut-off of TLC $[9,14]$. However conflicting results have been reported $[15,16]$.

Bivariate associations showed a high positive correlation between TLC and CD4 counts and the mean level of TLC increased with increased levels of CD4 for both HAART treated and HAART untreated patients. This is also consistent with the study by Wang et al. [14], among HIV patients from four countries that observed a high positive correlation between TLC and CD4 counts before and after initiating HAART. Similar relationship was observed in other studies from limited resource settings $[9,13]$. However, previous study by Mbanya et al. [17] reported a weak association between CD4 count and TLC and hence the limited value of TLC in predicting CD4 counts making it unsuitable to be substituted for CD 4 counts. These differences in findings could be as a result of different ethnic, racial, epidemiological, and socioeconomic factors [18] among study participants.

This study further showed that BMI and $\mathrm{Hb}$ could also provide some useful prognostic information about HIV disease progression. A sensitivity, specificity, and AUC of $73.9 \%, 56.8 \%$, and 0.688 for $\mathrm{Hb}$ and $69.9 \%, 80.1 \%$, and 0.780 for BMI, respectively, were observed in predicting CD4 counts $<200 \mathrm{~mm}^{-3}$. These levels of AUC based on Youden's $J$ index show a strong predictive ability of $\mathrm{Hb}$ and $\mathrm{BMI}$ at cut-offs of $12.15 \mathrm{~kg} / \mathrm{m}^{2}$ and $20.65 \mathrm{~g} / \mathrm{dL}$, respectively. However, when haemoglobin and BMI are used as a substitute for CD4 at these cut-offs some of the patients who require medication will not be given the needed medication due to relatively low sensitivity and specificity. Further, patients in the advanced stage of the disease cannot be clearly identified and given the needed attention and treatment should these cut-off points 
be used a surrogate for CD4 count in our settings. There was also a significantly positive correlation between these biomarkers and CD4 counts in the studied population and a trend analysis revealed that an increase in $\mathrm{Hb}, \mathrm{BMI}$, and TLC is associated with an increase in the level of CD4 counts. Previous studies $[19,20]$ have reported higher BMI to be associated with an increased CD4 counts, improved immune reconstitution, and improved survival resulting in a slower disease progression. The trend relationship between $\mathrm{Hb}$ and $\mathrm{CD} 4$ counts has also been confirmed in previous studies. Earlier reports have also demonstrated that low levels of haemoglobin may be associated with AIDS and death in people with HIV $[21,22]$ indicating the prognostic value of haemoglobin measurement in the disease progression as evidence in this study. The significant positive correlation observed between haemoglobin levels and CD4 count in the studied participants coupled with the decrease in haemoglobin levels as the disease progress is indicative that haemoglobin measurement may independently provide prognostic information provided by CD4 counts in economically disadvantaged settings.

\section{Conclusion}

The study has shown that TLC, $\mathrm{Hb}$, and BMI may provide some useful prognostic information independent of what is provided by the CD4 count. The regular measurement of these parameters in resource limited settings may therefore be useful to clinicians in monitoring patient's response to antiretroviral therapy and predicting the stage of the disease. This could possibly assist clinicians in identifying patients who are at higher risks of disease progression thereby reducing mortality caused by the HIV infection.

\section{Abbreviations}

BMI: Body mass index

HIV: Human immunodeficiency virus

HAART: Highly active antiretroviral therapy

TLC: Total lymphocyte count.

\section{Ethical Approval}

Ethical approval was sought from the committee on human research and publication of the School of Medical Science, Kwame Nkrumah University of Science and Technology (KNUST). Participation was voluntary and verbal informed consent was obtained from each participant according to Helsinki Declaration. Respondents were assured that the information gathered was to be used strictly for research and academic purpose only. In addition, respondents were given the freedom to opt out any time they thought they could not continue with the study.

\section{Conflicts of Interest}

The authors declare no conflicts of interest.

\section{Authors' Contributions}

Louis Boafo Kwantwi contributed to the research design, data analysis and interpretation of results, and first draft of the manuscript. Dan Yedu Quansah contributed to the conception of the research idea, interpretation of results, and first draft of the manuscript. Bismark Kwame Tunu contributed to data collection, design, and interpretation of results. Daniel Boateng contributed to data analysis and interpretation of results and critically reviewed the manuscript. Louis Boafo Kwantwi supervised all the work and had primary responsibility for the final content. All authors read and approved the manuscript for submission.

\section{Acknowledgments}

Gratitude goes to all patients who participated in the study.

\section{References}

[1] UNICEF and World Health Organization, "Global HIV/AIDS response: epidemic update and health sector progress towards universal access: progress report 2011," Tech. Rep., World Health Organization, Geneva, Switzerland, 2011.

[2] B. Denue, P. Ikunaiye, and Denue C., "Body mass index changes during highly active antiretroviral therapy in Nigeria/Modifications de l'indice de masse corporelle pendant le traitement antirétroviral hautement actif au Nigéria," Eastern Mediterranean Health Journal, vol. 19, no. 3, article S89, 2013.

[3] G. C. De Santis, D. M. Brunetta, F. C. Vilar et al., "Hematological abnormalities in HIV-infected patients," International Journal of Infectious Diseases, vol. 15, no. 12, pp. e808-e811, 2011.

[4] G. C. Davenport, C. Ouma, J. B. Hittner et al., "Hematological predictors of increased severe anemia in Kenyan children coinfected with Plasmodium falciparum and HIV-1," American Journal of Hematology, vol. 85, no. 4, pp. 227-233, 2010.

[5] A. Rios, "HIV-related hematological malignancies: a concise review," Clinical Lymphoma, Myeloma and Leukemia, vol. 14, pp. S96-S103, 2014.

[6] F. Bonnet, C. Lewden, T. May et al., "Malignancy-related causes of death in human immunodeficiency virus-infected patients in the era of highly active antiretroviral therapy," Cancer, vol. 101, no. 2, pp. 317-324, 2004.

[7] P. Balakrishnan, S. Solomon, N. Kumarasamy, and K. H. Mayer, "Low-cost monitoring of HIV infected individuals on highly active antiretroviral therapy (HAART) in developing countries," Indian Journal of Medical Research, vol. 121, no. 4, pp. 345-355, 2005.

[8] A. Sharma, S. A. Bynum, M. F. Schneider et al., "Changes in body mass index following HAART initiation among HIVinfected women in the women's interagency HIV study," Journal of AIDS and Clinical Research, vol. 5, no. 7, pp. 2-8, 2014.

[9] C. Obirikorang, L. Quaye, and I. Acheampong, "Total lymphocyte count as a surrogate marker for CD4 count in resourcelimited settings," BMC Infectious Diseases, no. 1, article 128, 2012.

[10] V. Kandi and A. B. Bhatti, "Advantages of Alternate Biomarkers in the Management of Human Immunodeficiency Virus with Highly Active Antiretroviral Therapy," in Science and Education Publishing, 2016.

[11] A. Sharma, D. R. Hoover, Q. Shi et al., "Relationship between body mass index and mortality in HIV-infected HAART users 
in the women's interagency HIV study," PLoS ONE, vol. 10, no. 12, Article ID e0143740, 2015.

[12] S. Shah, C. J. Smith, F. Lampe et al., "Haemoglobin and albumin as markers of HIV disease progression in the highly active antiretrovial therapy era: relationships with gender," $H I V$ Medicine, vol. 8, no. 1, pp. 38-45, 2007.

[13] D. Daka and E. Loha, "Relationship between Total Lymphocyte count (TLC) and CD4 count among peoples living with HIV, Southern Ethiopia: a retrospective evaluation," AIDS Research and Therapy, no. 1, article 26, 2008.

[14] Y. Wang, S. Liang, E. Yu et al., "Correlation analysis on total lymphocyte count and CD4 count in HIV-infected patients: a retrospective evaluation," Journal of Huazhong University of Science and Technology - Medical Science, vol. 31, no. 5, pp. 712716, 2011.

[15] A. L. D. Angelo, C. D. Angelo, A. J. L. Torres et al., "Evaluating total lymphocyte counts as a substitute for CD4 counts in the follow up of AIDS patients," Brazilian Journal of Infectious Diseases, vol. 11, no. 5, pp. 466-470, 2007.

[16] N. O. Akinola, O. Olasode, I. A. Adediran et al., "The search for a predictor of $\mathrm{CD} 4$ cell count continues: total lymphocyte count is not a substitute for CD4 cell count in the management of HIV-infected individuals in a resource-limited setting," Clinical Infectious Diseases, vol. 39, no. 4, pp. 579-581, 2004.

[17] D. Mbanya, F. Assah, N. Ndembi, and L. Kaptue, "Monitoring antiretroviral therapy in HIV/AIDS patients in resource-limited settings: CD4 counts or total lymphocyte counts?" International Journal of Infectious Diseases, vol. 11, no. 2, pp. 157-160, 2007.

[18] S. M. Alavi, F. Ahmadi, and M. Farhadi, "Correlation between total lymphocyte count, hemoglobin, hematocrit and CD4 count in HIV/AIDS patients," Acta Medica Iranica, vol. 47, no. 1, pp. 1-4, 2009.

[19] J. R. Koethe, C. A. Jenkins, B. E. Shepherd, S. E. Stinnette, and T. R. Sterling, "An optimal body mass index range associated with improved immune reconstitution among HIV-infected adults initiating antiretroviral therapy," Clinical Infectious Diseases, vol. 53, no. 9, pp. 952-960, 2011.

[20] C. Y. Jones, J. W. Hogan, B. Snyder et al., "Overweight and human immunodeficiency virus (HIV) progression in women: associations HIV disease progression and changes in body mass index in women in the HIV epidemiology research study cohort," Clinical Infectious Diseases, vol. 37, supplement 2, pp. S69-S80, 2003.

[21] A. J. Saah, D. R. Hoover, Y. He, L. A. Kingsley, and J. P. Phair, "Factors influencing survival after AIDS: report from the multicenter AIDS cohort study (MACS)," Journal of Acquired Immune Deficiency Syndromes, vol. 7, no. 3, pp. 287-295, 1994.

[22] C. Obirikorang and F. A. Yeboah, "Blood haemoglobin measurement as a predictive indicator for the progression of HIV/AIDS in resource-limited setting," Journal of Biomedical Science, vol. 16, no. 1, article 102, 2009. 


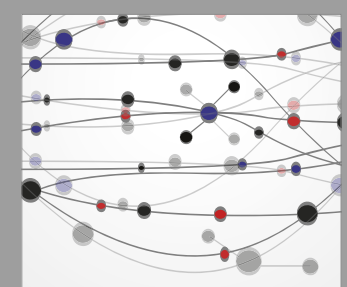

The Scientific World Journal
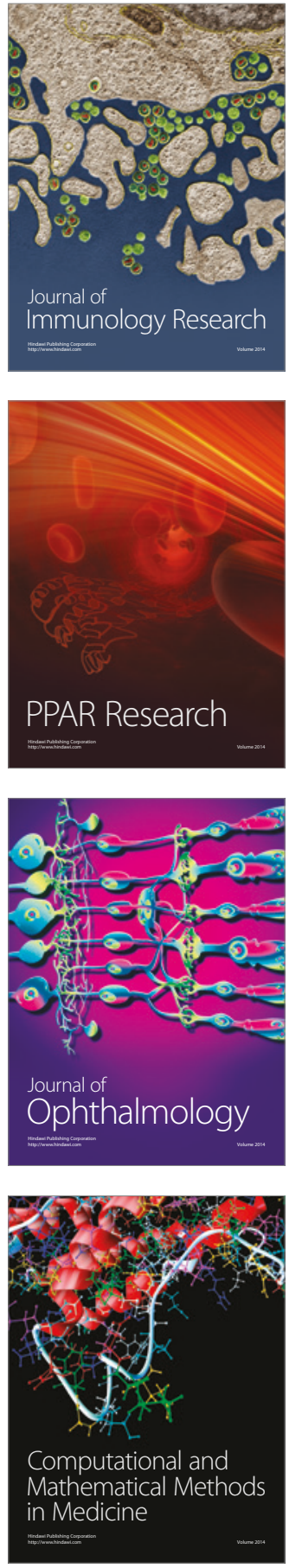

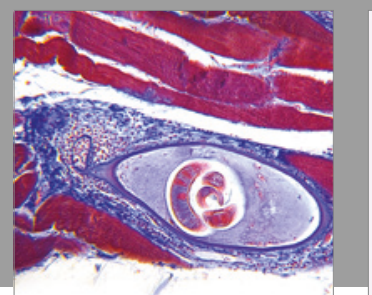

Gastroenterology Research and Practice
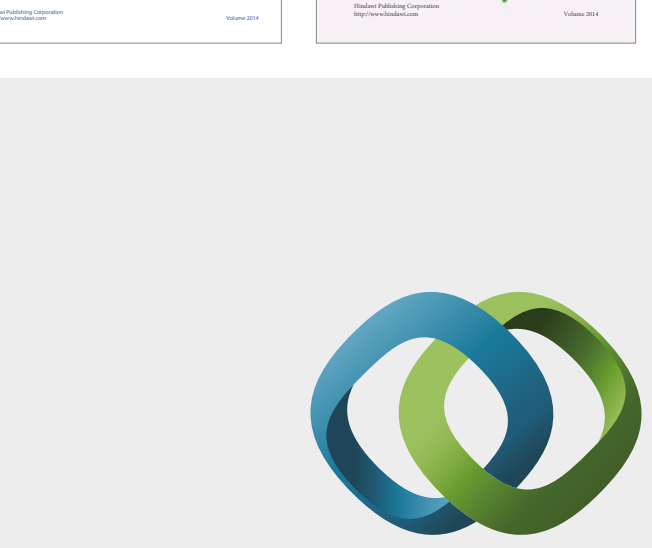

\section{Hindawi}

Submit your manuscripts at

https://www.hindawi.com
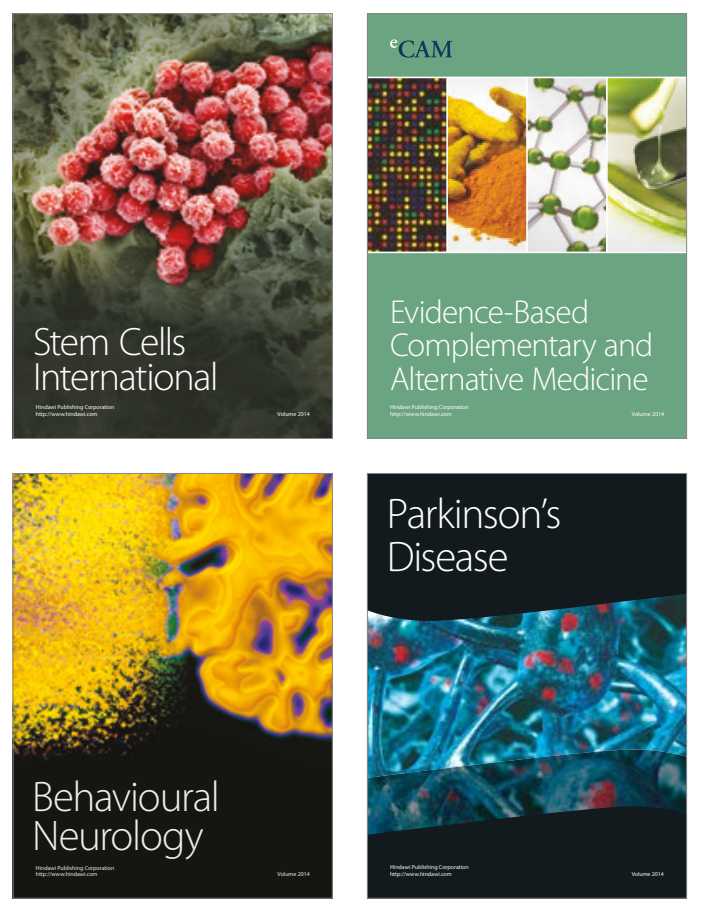
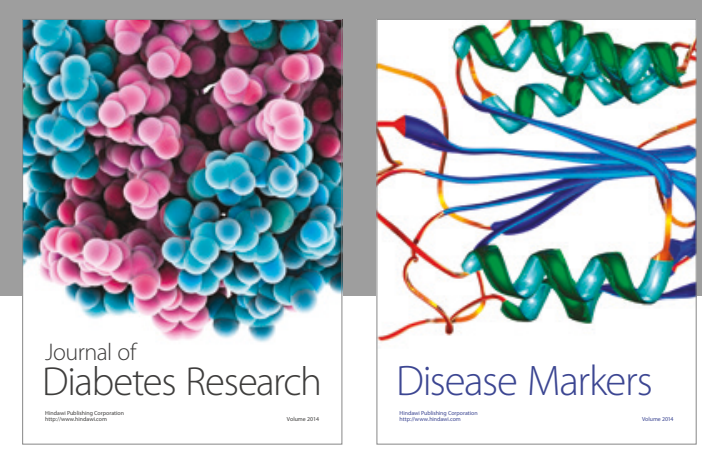

Disease Markers
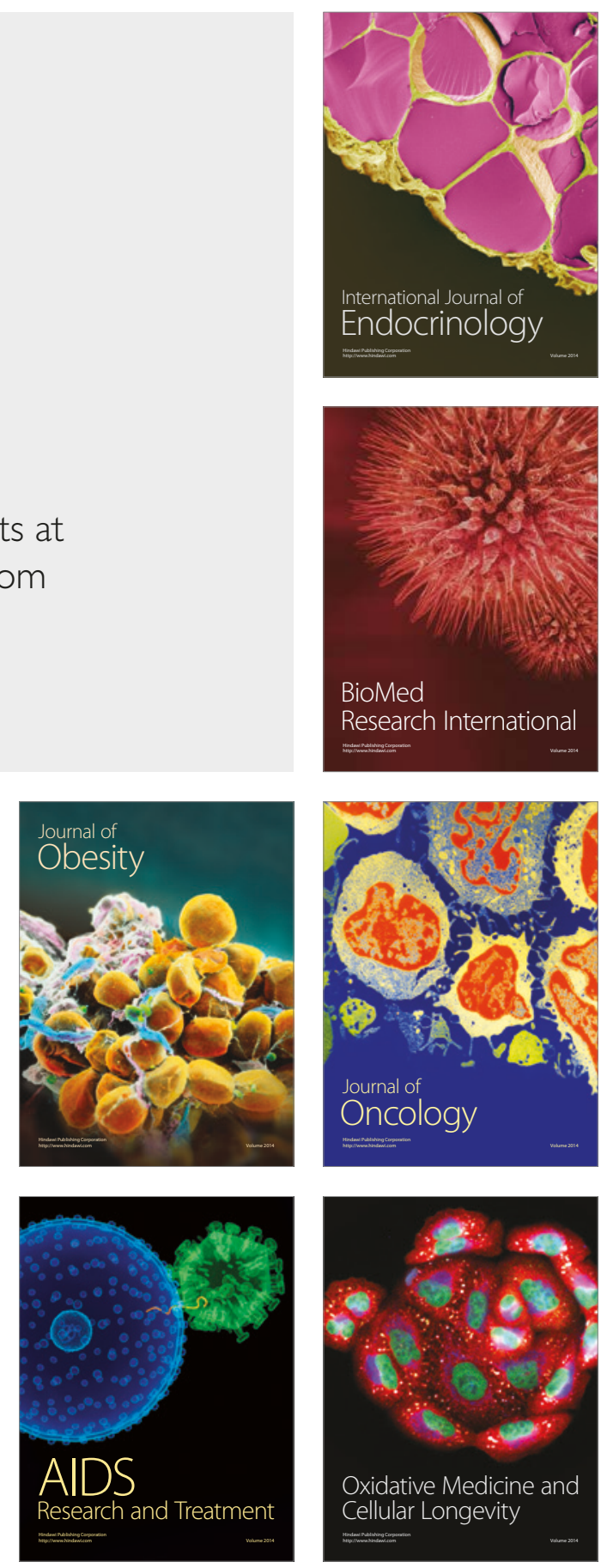